\title{
Attending to immigrants' everyday activities: A new perspective on ensuring Asian immigrants' quality of life
}

\author{
Hagyun Kim ${ }^{1}$ and Clare Hocking ${ }^{2}$
}

\begin{abstract}
INTRODUCTION: The quality of Asian immigrants' lives is significant to the harmony of New Zealand society where, at the 2013 Census, $11.8 \%$ of its residents identified as Asian. However, settlement can be stressful for new Asian immigrants because moving to a country with a different culture can disrupt most of their familiar routines, and it is strongly associated with marginalisation and isolation from society. Recognising these challenges, social workers have positioned themselves at the forefront of efforts to improve Asian immigrants' quality of life.

METHOD: An occupational perspective is applied to underpin an examination of Asian immigrants' participation in Aotearoa New Zealand society. Occupational science is a basic social science grounded in the notion that people engage in occupations for their existence and that the drive to be occupied has evolutionary, psychological, social, and symbolic roots.

CONCLUSIONS: This article suggests an occupational perspective as a new analytic framework which has the potential to give social workers clearer insight into the realities which Asian immigrants encounter; consequently, increasing their ability to support Asian immigrants' full participation into a new society.
\end{abstract}

KEYWORDS: Asian immigrants, occupation, occupational perspective, settlement

\section{Introduction}

New Zealand is one of the popular destinations where potential immigrants desire to re-establish their lives. In part, New Zealand's attraction may have been enhanced by the discourse about biculturalism which has increased New Zealand society's cultural responsiveness (Nayar, 2013). The 2013 Census reported that $74 \%$ of New Zealand's population were of European ethnic origin, 14.9\% Māori, $11.8 \%$ Asian and $7.4 \%$ Pacific, accompanied by 1.2 per cent emerging ethnic groups from Middle Eastern, Latin American and African countries.

In response to the ethnic diversity of New Zealand's population, the New Zealand government aims to build an inclusive society where all members fully participate in their communities (Ministry of Social Development, 2003). This goal has led to the establishment of a wide range of resettlement services to accommodate immigrants' cultural needs and assist them to deal with the challenges of integration (Department of Labour, 2007). From this perspective, it is necessary to understand the characteristics of New Zealand's diverse ethnic communities separately where possible. This knowledge will help immigrants to become contributing members of their new communities.

From amongst all the diverse ethnic groups in New Zealand, this article focuses on the Asian population, which dramatically increased over recent decades (Ho, 2015),
${ }^{1}$ Department of Public Health and Psychosocial Studies, Auckland University of Technology, Auckland, New Zealand

${ }^{2}$ Department of Occupational Science and Therapy, Auckland University of Technology, Auckland, New Zealand

AOTEAROA NEW ZEALAND SOCIAL WORK 28(3), 57-66.

CORRESPONDENCE TO: Hagyun Kim Hagyun.kim@aut.ac.nz 
and suggests a new analytic framework, an occupational perspective, to give a better understanding of the experiences of Asian immigrants settling in New Zealand.

\section{The Asian population in New Zealand}

The Immigration Act Review of 1986 instigated a changed pattern of immigration and contributed to increasing numbers of Asian immigrants into New Zealand's society (Bedford, Callister, \& Didham, 2010). According to this report, Asian immigrants were expected to strengthen national prosperity (Spoonley \& Gendall, 2010), leading to the Immigration Act of 1987 in which new immigrants would be selected based on their personal merits rather than their national or ethnic origins (Cheyne, O’Brien, \& Belgrave, 2008).

With governmental acknowledgement that immigrants from Asia would bring valuable skills and make financial contributions to the economy (McKinnon, 1996), the 1987 immigration policies opened the door to Asian immigrants. As a result, the number of Asian residents rapidly increased from less than $2 \%$ of the population in 1986, to 11.8\% in 2013 (Statistics New Zealand, 2013). In $2013,471,711$ people who self-identified with Asian ethnicities resided in New Zealand and their number is predicted to reach $24 \%$ of the total population by 2021 .

Asian people come from a vast region that contains over $60 \%$ of the world's population, east of and including Afghanistan, and south of and including China (Ho, 2015). It is almost impossible to understand Asian populations as a whole, as they are made up of diverse ethnic sub-groups such as Chinese, Indian, Filipino, and Korean. Each Asian ethnic group has their own unique cultural and linguistic background, demographic characteristics, and health, education and socio-economic status (Ho, Au, Bedford, \& Cooper, 2002).

Thus, there are "the multiple dimensions of difference within New Zealand's Asian communities" (Ho, 2015, p. 97).
Several researchers, however, have made a major contribution to understanding the characteristics of the Asian population in New Zealand (Abbott, Wong, Williams, Au, \& Young, 2000; Bedford et al., 2010; Epstein, 2006; Ho, 2015; Ho et al., 2002; McKinnon, 1996; Nayar, 2013). For example, Epstein (2006) postulated that immigration to New Zealand entails a complex process of re-negotiating identity in which Korean immigrants maintain a hybrid KoreanNew Zealand identity, whereas Ho (2015) elaborated the changing characteristics of the Asian population under six themes including: more diverse Asian ethnic groups, changing age-sex structure, different labour market experiences, growing mobility and transnational connections, complex patterns of mixed ethnicity, and increased concentration in Auckland.

These authors agreed that, for Asian immigrants, immigration itself is a highly complex process that produces similar levels of stress despite their different ethnicities and attributes. Many Asian immigrants encounter some level of physical, socio-cultural, political, economical/ environmental change, which can have a significant impact on all aspects of their lives.

\section{Issues Asian immigrants encounter in New Zealand}

The receiving communities of migrants need to be well prepared if they are to accept immigrants and refugees. Host populations need to be educated through publicity campaigns and integration projects to assist the settlement process for immigrants and refugees. Host children need to know more about the lives and customs of children from different ethnic backgrounds. (Nash, 2005, p. 152)

As Nash (2005) postulated, the increasing diversity of New Zealand's population means that all citizens need to be able to understand and interact with each other regardless of their cultural backgrounds. 
This effort will enhance societal responsiveness to new comers and empower this population to access and maximise relevant and necessary support to be part of society.

A basis for social responsiveness and support can be identified in New Zealand's history. Given its legislative foundation in the 1840 Treaty of Waitangi, it can be argued that New Zealand is historically bicultural (Nayar, 2013). In this context, indigenous people's rights of participation, partnership and protection are protected (Cheyne et al., 2008), forming a cultural safety framework for New Zealand society by which cultural respect and power relationships are critically considered (Lim \& Iwama, 2006). This provides the foundation for multiculturalism in which ethnic minorities can reach their full potential whilst maintaining their culture (Nayar, 2009), leading to the fact that $86 \%$ of immigrants reported living satisfactorily in New Zealand (Department of Labour, 2008).

However, there are growing concerns that many Asian immigrants face formidable barriers to accessing the full benefits of an inclusive society, which are associated with the loss of cultural norms, language, religious customs and social support systems (Chang, Morris, \& Vokes, 2006; Ho, 2015). They encounter great pressure to relinquish many things they hold dear in order to gain entry to another culture (Kim, Hocking, McKenzie-Green, \& Nayar, 2016), with the resulting effect that there is "too much to know and too much to do" (Suleman \& Whiteford, 2013, p. 201).

Asian immigrants are also vulnerable to racism, given the fact that they were reported to be one of the most discriminated against groups in New Zealand (Statistics New Zealand, 2012). Spoonley and Gendall (2010) revealed that the majority of New Zealanders were ill-equipped to deal with Asian immigrants' sudden appearance and remained suspicious of their different cultures. This attitude is often associated with resistance, and hostility is influenced when the media focus on the negative aspects of the Asian inflow (Cheyne et al., 2008), limiting Asian immigrants' capacity to participate in civic society.

Asian immigrants thus have to find ways of creating a new home and negotiating their ethnic identities with limited knowledge, support and resources whilst dealing with prejudice against them within New Zealand society. For many Asian immigrants, the significant socioenvironmental changes which they inevitably experience may compromise their capacity in their participation in civic society and this is clearly seen by the differences in levels of income, health status, educational attainment, and employment (Scragg, 2010), leading to a sense of being second-rate citizens, whether politically or economically (Kim et al., 2016; Mueller, 2006).

\section{The role of social workers in supporting Asian immigrants}

Asian people in New Zealand remain more highly educated than other New Zealanders; but they have lower incomes and are more likely to live in more economically deprived areas than Europeans, which limits their options for making healthy lifestyle choices. (Scragg, 2010, p. 3)

Immigration, the action of transitioning to a new country, has the potential to adversely impact individuals' health and wellbeing, as their capacity to participate in meaningful life is limited (Connor Schisler \& Polatajko, 2002). It has been argued that resettlement stress undermines Asian immigrants' health (Abbott et al., 2000; Mehta, 2012). Furthermore, Asian immigrants' limited capacity to participate in civic society is a breach of the United Nations' Human Rights Declaration, which clearly states that all human beings are equal in dignity and rights (United Nations, 1948). In response, the authors suggest that social work is a profession that can effectively empower Asian immigrants to overcome the problems of being an ethnic minority in their new community. 
The major goal of social work is to increase individuals' social skills and social opportunities, alongside strengthening the community's capacities to solve problems (Specht \& Courtney, 1994). This function fits well when social workers work with individual Asian immigrants with limited ability to engage in the host society, while assisting the host society to develop support programmes which address transitional life challenges and consequently enhance newcomers' wellbeing.

In reality, many social workers already actively engage in related activities to support Asian immigrants to re-build their lives, as part of complying with their mission; that is to "alleviate social suffering and improve the quality of people's lives" (van Heugten, 2001, p. 14). This includes educating Asian migrant clients to resolve problems whilst linking them with needed resources at the micro level, developing community resources at the meso level, and initiating social services and developing social policies at the macro level (Shulman \& Shedlin, 2009).

In response to the demographic change, the Social Workers Registration Board of New Zealand (SWRB) also emphasises its members' ability to work with diversity as one of its ten core competence standards (SWRB, 2015). Currently, social workers should have sufficient knowledge of diversity between and within different cultures including ethnicity. Additionally, in the health sector, where significant numbers of social workers work, the New Zealand government gives District Health Boards responsibility to develop culturally responsive services for Asian immigrant groups and requests health professionals to improve their cultural competence to respectfully and effectively work with a diverse range of people (Mehta, 2012).

However, it is the concern of the first author, as a fellow social worker with an immigrant background, that social workers' understanding of Asian immigrants' experiences is often hampered by insufficient resources which do not reflect the new realities of the New Zealand population (NZAsia Foundation, 2009). Furthermore, given how suddenly the Asian population appeared (Ho, 2015), the first author has witnessed that social workers with mainstream backgrounds have less experience with Asian cultures and therefore struggle to understand Asian immigrants' life situations. It is perhaps not surprising, as Connolly (2001) attested, that what people bring to a situation depends on what they have learned and experienced previously.

In the next section, we will introduce a new analytic framework, an occupational perspective. By attending to people's everyday activities (Wilcock, 2001), this perspective can assist social workers to understand what it is like to be ethnic immigrants and how they interpret situations from the perspective of their specific religion, culture, and language.

\section{Occupational perspective}

Given that immigration is a process of adaptation (Berry, 1997), adopting an occupational perspective that attends to people's everyday occupations has the potential to enrich social workers' understandings of what is happening to Asian immigrants as they adapt to a new culture whilst re-building their everyday lives. That perspective is promoted by occupational science, which was established in the late 1980s to study the relationships between people and what they do on a daily basis (Wilcock \& Hocking, 2015).

Occupational science is a basic social science grounded in the notion that people engage in occupations for their existence and that the drive to be occupied has evolutionary, psychological, social, and symbolic roots (Yerxa, Clark, Jackson, Pierce, \& Zemke, 1990). A key feature of this scientific perspective is to examine the form, function and meaning of occupations in people's lives. 


\section{Occupation}

As noted above, the term occupation is the central concept of occupational science (Creek, 2010). Occupation is not narrowly interpreted as employment; rather it encompasses "every activity in which a person participates over the course of a day, week, month, year or life" (Njelesani, Cameron, \& Polatajko, 2012, p. 36). The perspective taken is to examine what people do on their own or collectively and how people seek identity. In that context, occupations can be conceptualised as doing, being, becoming and belonging (Wilcock \& Hocking, 2015).

\section{Doing}

Doing encompasses all the activities that people perform in order to carry out their daily lives, and incorporates physical, social, psychological, emotional, and spiritual dimensions. The everyday activities people want, need and are expected to do are commonly categorised as self-care, productivity and leisure (Townsend \& Polatajko, 2007).

Self-care is all about maintenance, from personal care to community living. It encompasses any activity where the intention is to stay physically and mentally fit (Creek, 2010). Occupations in self-care generally include those activities that are necessary for the maintenance of self within the environment, such as preparing meals, dressing, banking, and even shopping; in summary, activities related to looking after oneself (Kielhofner, 2009).

Productivity is associated with activities with which people support self, family and society through the production of goods and services. Productive activities are a deeply generative and integrative force in people's lives, with the way that they express themselves being closely tied to what they do for a living (Whiteford, 2010). Activities in this area also closely relate to life satisfaction, resulting in changed perceptions of self in positive ways (Law, Steinwender, \& Leclair, 1998).
Leisure is characterised as "a measurable residue of time, clearly distinguished by an absence of constraint and an abundance of something called discretion" (Suto, 1998, p. 273). Participation in leisure is a key component of people's occupational repertoire as it often provides a suspension of reality, leading to increased life satisfaction, freedom from obligation, freedom of choice, enjoyment, relaxation, self-expression, and internal locus of control.

Through engagement in activities across these three domains, people interpret and comprehend the world, and make their place in the world (Yerxa et al., 1990). This makes it clear that occupation is as old as humanity because people have to do these activities for survival, and doing so connects them to social and cultural environments (Kielhofner, 2009).

\section{Being, becoming and belonging}

Life meaning, a person's being, and occupation are inseparable (Hasselkus, 2011). Given that being refers to "the essential nature of someone; their essence or substance, soul, spirit, psyche, or core; their inner person or persona" (Wilcock \& Hocking, 2015, p. 180), a person's being is largely shaped by their daily patterns of occupational participation.

In everyday life, people's occupations are the basis for how they feel about themselves and determine their relationships with others. Through a reflexive process in which they make choices about how to occupy their time, people give life meaning and forge their being (Kielhofner, 2009).

Additionally, occupational science posits that people's history of occupational participation determines their becoming (Forsyth \& Kielhofner, 2006). People set goals throughout life, and through occupations they achieve these goals and experience success and selfefficacy; that is to say, "it is through doing that people become what they have the potential to be" (Wilcock, 2001, p. 413). 
Belonging is experienced as the ease and familiarity of doing things with others (Wilcock \& Hocking, 2015). Being accepted and knowing that people belong is strongly aligned to a sense of fitting in, being suitable, or acceptable, as well as being included and feeling secure in what people are doing (Wilcock, 2001). It is through doing things with others that bonds are created and a sense of belonging is established within family, friends, and wider communities.

As such, in the occupational science literature, a person's self is "to a large extent occupational in nature, as one performs mainly through 'doing' in order to be, become, and belong" (Huot \& LaliberteRudman, 2010, p. 72). A person's sense of who they are and can become is articulated through their daily patterns of occupations which have personal, cultural, and spiritual value to the individual; in other words, the self is largely constructed by participation in occupation.

\section{Health and wellbeing}

Health is now widely recognised to relate to how people achieve a productive and fulfilling life regardless of their health conditions (Wilcock \& Hocking, 2015). According to the World Health Organisation (WHO, 2001), health is created within the settings of people's everyday life; where they learn, work, and play. This assertion clearly indicates that health is determined by participation, which is embedded in occupation (Townsend \& Polatajko, 2007). In this sense, people's actual experiences of everyday occupations are the primary resources for good health.

Attending to a person's engagement in everyday occupations is consistent with the Ottawa Charter for Health Promotion (WHO, 1986), which identified preparation for living (education), the outcomes of human productivity (shelter, food, income), and its social and environmental conditions (peace, justice, a stable ecosystem, sustainable use of resources) as the prerequisites of health.
Wellbeing refers to a perceived state of harmony in all aspects of one's life at an abstract level including self-acceptance, positive relations with others, autonomy, environmental mastery, purpose in life, and personal growth (Hasselkus, 2011). These dimensions can be satisfied by engaging in occupations which provide a sense of reality and achievement, and improve one's sense of fulfilment and self-esteem (Law \& Baum, 2001). It is engagement in occupation that helps people find their purpose and meaning in life and this experience eventually increases a sense of wellbeing; that is to say, "life without occupation would be tenuous, and the experience of wellbeing would be nigh unto impossible" (Hasselkus, 2011, p. 60).

\section{Occupational science studies in immigration}

Occupational science is grounded in the belief that people are most true to their humanity when they engage in occupations (Yerxa et al., 1990). Health, wellbeing and survival are viewed as dependant on a person's opportunities and resources for participation in health-building occupations (Wilcock \& Hocking, 2015). This assertion has the potential to assist social workers to listen closely to immigrants' everyday occupational needs, and consequently increase their capacity to help immigrants find a place in their new country.

In occupational science, humans are believed to be in reciprocal interaction with their environments (Connor Schisler \& Polatajko, 2002). This perspective clarifies that people are inevitably conditioned by the contexts in which they find themselves; yet they are active in relation to their environment. Through that lens, people are viewed as adapting through transactions with all elements of their environments. This makes it possible to conclude that immigrants adapt to a new culture by seeing themselves as social objects, and they can only do that through social interaction, where the means of interacting is through engagement in occupations (Whiteford, 2010). 
This suggests that using occupation as a unit of analysis can provide insights into the adjustment process of immigration and will help to understand the lives of immigrants by exploring what they actually do as they interact with people in their new communities (Gupta \& Sullivan, 2013). Research in occupational science reveals that immigration is a major life-transition that disrupts people's established occupations and subsequently impacts on their quality of life. For example, Connor Schisler and Polatajko (2002) found that immigrants adapt to a new society by sorting activities into same, altered, added, and abandoned, whilst Nayar (2009) discovered immigrants navigate cultural spaces to continue their occupations. Huot and Laliberte-Rudman (2010) also commented that immigrants negotiate integration through occupation following immigration.

From this perspective, the process of settlement can be conceptualised as an occupational transition (Gupta \& Sullivan, 2013) in relation to how immigrants navigate occupations within various social circumstances (Huot \& Laliberte-Rudman, 2010). This knowledge makes it possible to hypothesise that occupations are mediating devices with which immigrants adapt to a new environment and when their occupational choices are out of balance, their health and wellbeing are compromised (Nayar, 2009).

\section{Discussion}

In an attempt to understand the varied experiences of immigrants, the term acculturation has been most commonly used to explain the demands and results of crosscultural relocations (Santisteban \& Mitrani, 2002). Berry (2001) defined acculturation as "a process that entails contact between two cultural groups, which results in numerous cultural changes in both parties" (p. 616). The focus of acculturation is on how individuals, who left one social unit and entered another, manage to adapt to new contexts through interaction with the receiving culture.
Acculturation is considered to be a selective process available to immigrants through which they adapt to new value systems and transform personality traits, including assimilation, separation, marginalisation and integration (Krishnan \& Berry, 1992). Eventual choice of one of these processes largely depends on how the acculturating individual answers two questions; cultural maintenance and contact and participation (Berry, 2001).

It is clear that the concept of acculturation, particularly Berry's model (1994, 1997, 2001), has contributed to an increase in knowledge of immigrants' experiences. However, because this model predominantly views assimilation as "inevitable when dominant and minority groups cohabit" (Deutscher, 2004 , p. 450), it is questionable how this model reflects today's world environment where "immigration is no longer viewed as a permanent one-way movement" (Ho, 2015, p. 108).

Within the context of globalisation, propelled by developments in transportation and communications, it is almost impossible for immigrants to be totally disconnected from the origin of their world and assimilate into the culture of the host society (Kim et al., 2016). Instead, they frequently communicate with their home country via diverse technologies, thus adapting to transnational connections during the acculturation process (Ho, 2015).

This means social workers should reconsider the traditional belief of acculturation models, whereby the acculturative process of immigration is a unidirectional course of cultural change eventually resulting in full assimilation (Deutscher, 2004). In this sense, the concept of "recycling the old me into the new me through occupations" (Clark, Ennevor, \& Richardson, 1996, p. 374) can be useful in understanding the complexity of being a member of an ethnic minority in a multicultural society.

The concept of recycling can help social workers who use the ecological approach to 
analyse the complex transactions between people and their environments (Payne, 2005). For example, at the micro level, through exploring what people do every day, social workers can identify how Asian immigrants' daily activities remain the same, or are altered, added or abandoned as a result of the merging of two cultures (Connor Schisler \& Polatajko, 2002). This knowledge will lead to further understanding of how Asian immigrants navigate cultural spaces to perform activities within the community at the meso level (Nayar, 2009), and contribute to social workers developing policies to assist Asian immigrants to regain control over their disrupted activities at the macro level (Kim et al., 2016). As such, bringing an occupational perspective to the challenges experienced by Asian immigrants will produce knowledge with which social workers can effectively empower Asian immigrants to sustain health and wellbeing in a new country.

A distinguishing feature of social work is to consider clients' situations alongside family, community, and society, to help them continue normal life tasks (Specht \& Courtney, 1994). This inspires social workers to be ready to strengthen individual immigrants' functioning and develop societal structures that provide resources and maximise opportunities for participation in civic society. To achieve this, this paper suggests that social workers seek out occupational science research, literature and training. From that perspective, they can explore what immigrants actually do to adjust after immigration. Concurrently, social workers can increase their knowledge of how immigrants connect with different places through their occupations and subsequently facilitate full participation in their new communities.

Lastly, attending to immigrants' everyday occupations aligns with the New Zealand Settlement Strategy (NZSS), which aims to assist immigrants to participate in society by 1) feeling welcomed and accepted, 2) being in the right job, 3) being housed well, 4) speaking and understanding New Zealand English, 5) knowing how to access information and services, and 6) understanding the New Zealand way of life and knowing that they are contributing to it (Department of Labour, 2007). The emphasis of the NZSS is clearly on immigrants' everyday occupational needs such as jobs, housing, schools, and health systems.

Based on the NZSS, a number of settlement services have been established to support immigrants in the adaptation phase, while self-help groups have emerged which are involved in the integration phase of settlement (Nash, 2005). For example, Settlement Support New Zealand is an Immigration New Zealand initiative which provides a local contact to newcomers through 18 offices around the country. The Chinese New Settlers Services Trust (CNSST) is a local initiative in Auckland which offers culturally and linguistically appropriate services to Asian immigrants, providing workshops such as New Zealand Law and Legislation, Home Ownership, or Road Safety Campaign (CNSST, 2014).

The NZSS was designed to assist newly arrived immigrants to learn how to perform occupations reflective of New Zealand society and as a result, feel a sense of belonging in their new community, and confidence that they are able to judge what actions are appropriate to the place. In other words, the focus of the NZSS is on helping immigrants to know how daily occupations are done within the New Zealand context. Employing an occupational perspective holds promise for gaining an in-depth understanding of immigrants' occupational needs.

\section{Conclusion}

Social work is a profession which draws on a wide range of theories. Much of social work theory is co-constructed with other professions, leading to the recommendation that bringing an occupational perspective to Asian immigrants' settlement issues 
might be a route forward for social workers to understand their everyday needs and to assist them to achieve an acceptable quality of life in New Zealand. This article suggests that social workers' capacity to work with Asian immigrants will be strengthened by exploring what Asian immigrants actually do whilst they interact with a new culture. The occupational perspective has relevance for social workers faced with the growing challenges of meeting the needs of a diverse range of people.

\section{References}

Abbott, M. W., Wong, S., Williams, M., Au, M. K., \& Young, W. (2000). Recent Chinese migrants' health, adjustment to life in New Zealand and primary health care utilisation. Disability and Rehabilitation, 22(1/2), 43-56. doi:10.1080/096382800297114

Bedford, R., Callister, P., \& Didham, R. (2010). Arrivals, departures and net migration, 2001/02-2008/09. In A. Trlin, P. Spoonley \& R. Bedford (Eds.), New Zealand and international migration: A digest and bibliography, Number 5 (pp. 50-103). Auckland, New Zealand: Massey University.

Berry, J. W. (1994). An ecological perspective on cultural and ethnic psychology. In E. Trickett, R. Watts \& D. Birman (Eds.), Human diversity (pp. 115-141). San Francisco, CA: Jossey-Bass Inc.

Berry, J. W. (1997). Immigration, acculturation, and adaptation. Applied Psychology, 46(1), 5-68. doi:10.1111/j.14640597.1997.tb01087.x.

Berry, J. W. (2001). A psychology of immigration. Journal of Social Issues, 57(3), 615-631. doi:10.1111/0022-4537. 00231

Chang, S., Morris, C., \& Vokes, R. (2006). Korean migrant families in Christchurch: Expectations and experiences. Wellington, New Zealand: The Families Commission.

Cheyne, C., O'Brien, M., \& Belgrave, M. (2008). Social policy in Aotearoa New Zealand ( $4^{\text {th }}$ ed.). Melbourne, Australia: Oxford University Press.

Chinese New Settlers Services Trust. (2014). Retrieved February 10, 2014, from http://www.chineseservice.org. nz/en/

Clark, F., Ennevor, B., \& Richardson, P. L. (1996). A grounded theory of techniques for occupational storytelling and occupational story making. In R. Zemke \& F. Clark (Eds.), Occupational science: The evolving discipline (pp. 373-392). Philadelphia, PA: F. A. Davis.

Connolly, M. (2001). The art and science of social work. In M. Connolly (Ed.), New Zealand social work; Context and practice (pp. 18-31). Auckland, New Zealand: Oxford University Press.

Connor Schisler, A. M., \& Polatajko, H. J. (2002). The individual as mediator of the person-occupationenvironment interaction: Learning from the experience of refugees. Journal of Occupational Science, 9(2), 82-92. doi:10.1080/14427591.2002.9686496

Creek, J. (2010). The core concepts of occupational therapy. London, UK: Jessica Kingsley.
Department of Labour. (2007). Settlement national action plan: New Zealand settlement strategy. Wellington, New Zealand: Author.

Department of Labour. (2008). Life in New Zealand: Settlement experiences of skilled migrants. Wellington, New Zealand: Author.

Deutscher, I. (2004). Little theories and big problems: Chicago sociology and ethnic conflicts. Symbolic Interaction, 27(4), 441-459.

Epstein, S. (2006). Imagining the community: Newspapers, cyberspace and the (non-) construction of Korean New Zealand identity. In H. Johnson \& B. Moloughney (Eds.), Asia in the making of New Zealand (pp. 147-162). Auckland, New Zealand: Auckland University Press.

Forsyth, K., \& Kielhofner, G. (2006). The model of human occupation. In E. Duncan (Ed.), Foundation for practice in occupational therapy ( $4^{\text {th }}$ ed., pp. 69-108). London, UK: Elsevier Churchill Livingstone.

Gupta, J., \& Sullivan, C. (2013). The central role of occupation in the doing, being and belonging of immigrant women. Journal of Occupational Science, 20(1), 23-35. doi:10.1080/14427591.2012.717499

Hasselkus, B. R. (2011). The meaning of everyday occupation. Thorofare, NJ: Slack.

Ho, E. (2015). The changing face of Asian people in New Zealand. New Zealand Population Review, 41, 95-118.

Ho, E., Au, S., Bedford, C., \& Cooper, J. (2002). Mental health issues for Asians in New Zealand. Wellington, New Zealand: The Mental Health Commission.

Huot, S., \& Laliberte-Rudman, D. (2010). The performance and places of identity: Conceptualising intersections of occupation, identity, and place in the process of migration. Journal of Occupational Science, 17(2), 68-77. doi:10.1080/14427591.2010.9686677

Kielhofner, G. (2009). Conceptual foundations of occupational therapy practice $\left(4^{\text {th }}\right.$ ed.). Philadelphia, PA: F. A. Davis.

Kim, H., Hocking, C., McKenzie-Green, B., \& Nayar, S. (2016). Occupational experiences of Korean immigrants settling in New Zealand. Journal of Occupational Science. 23(2), 181-195 doi:10.1080/14427591.2015.1126168

Krishnan, A., \& Berry, J. W. (1992). Acculturative stress and acculturation attitudes among Indian immigrants to the United States. Psychology and Developing Societies, 4(2), 187-211.doi:10.1177/097133369200400206

Law, M., \& Baum, C. M. (2001). Measurement in occupational therapy. In M. Law, C. M. Baum \& W. Dunn (Eds.), Measuring occupational performance: Supporting best practice in occupational therapy (pp. 3-19). Thorofare, NJ: Slack.

Law, M., Steinwender, S., \& Leclair, M. (1998). Occupation, health and well-being. Canadian Journal of Occupational Therapy, 65(2), 81-91.

Lim, K., \& Iwama, M. (2006). Emerging models: An Asian perspective. In E. Duncan (Ed.), Foundation for practice in occupational therapy (4th ed., pp. 161-189). London, UK: Elsevier Churchill Livingstone.

McKinnon, M. (1996). Immigrants and citizens: New Zealanders and Asian immigration in history context. Wellington, New Zealand: Victoria University of Wellington. 
Mehta, S. (2012). Health needs assessment of Asian people living in the Auckland region. Auckland, New Zealand: Northern DHB Support Agency.

Ministry of Social Development. (2003). Statement of intent 2003. Wellington, New Zealand: Author.

Mueller, C. (2006). Integrating Turkish communities: A German dilemma. Population Research and Policy Review, 25(5/6). doi:10.1007/s11113-007-9024-y

Nash, M. (2005). Responding to settlement needs: Migrants and refugees and community development. In M. Nash, R. Munford \& K. O'Donoghue (Eds.), Social work theories inaction (pp. 140-154). London, UK: Jessica Kingsley.

Nayar, S. (2009). The theory of navigating cultural spaces. Unpublished doctoral thesis, Auckland University of Technology, Auckland, New Zealand.

Nayar, S. (2013). The treaty of Waitangi: Framing immigrants' occupational practices in Aotearoa New Zealand. Journal of Occupational Science, 20(4), 382-395. doi:10.1080/14427591.2013.801102

Njelesani, J., Cameron, D., \& Polatajko, H. (2012). Occupation-for-development: Expanding the boundaries of occupational science into the international development agenda. Journal of Occupational Science, 19(1), 36-43. doi:10.1080/14427591.2011.639665

NZAsia Foundation. (2009). Asia: Aware - why Asia matters to New Zealand. Retrieved March 28, 2014, from http://asianz.org.nz/sites/asianz.org.nz/files/AsiaNZ-Asia\%20 Aware_Why\%20Asia\%20matters\%20to\%20NZ.pdf

Payne, M. (2005). Modern social work theory ( $3^{\text {rd }}$ ed.). New York, NY: Palgrave Macmillan.

Santisteban, D. A., \& Mitrani, V. B. (2002). The influence of acculturation processes on the family. In K. M. Chun, P. B. Organista \& G. Marin (Eds.), Acculturation: Advances in theory, measurement, and applied research (pp. 121-135). Washington, WA: American Psychological Association.

Scragg, R. (2010). Asian Health in Aotearoa in 2006-2007: Trends since 2002-2003. Auckland, New Zealand: Northern DHB Support Agency.

Shulman, L. C., \& Shedlin, M. G. (2009). Focus group. In A. Gitterman \& R. Salmon (Eds.), Encyclopedia of social work with groups (pp. 136-139). New York, NY: Taylor \& Francis.

Social Workers Registration Board. (2015). Core competence standards. Wellington, New Zealand: Author. Retrieved December 17, 2015, from http://www.swrb.govt.nz/ competence-assessment/core-competence-standards

Specht, H., \& Courtney, M. (1994). Unfaithful angels: How social work has abandoned its mission. New York, NY: The Free Press.

Spoonley, P., \& Gendall, P. (2010). Welcome to our world Attitudes to immigrants and immigration. In A. Trin, P. Spoonley \& R. Bedford (Eds.), New Zealand and international migration: A digest and bibliography, number 5 (pp. 136-158). Auckland, New Zealand: Massey University.

Statistics New Zealand. (2012). Working together: Racial discrimination in New Zealand. Wellington, New Zealand: Author.

Statistics New Zealand. (2013). Number of overseas-born tops 1 million, 2013 Census shows. Retrieved August
26, 2014, from http://www.stats.govt.nz/Census/2013census/profile-and-summary-reports/qstats-cultureidentity-nz-mr.aspx

Suleman, A., \& Whiteford, G. E. (2013). Understanding occupational transitions in forced migration: The importance of life skills in early refugee resettlement. Journal of Occupational Science, 20(2), 201-210. doi:10.1080/14427591.2012.755908

Suto, M. J. (1998). Leisure in occupational therapy. Canadian Journal of Occupational Therapy, 65(5), 271-278.

Townsend, E., \& Polatajko, H. J. (2007). Enabling occupation II: Advancing an occupational therapy vision for health, well-being \& justice through occupation. Ontario, Canada: Canadian Association of Occupational Therapists Publications.

United Nations. (1948). The universal declaration of human rights. New York, NY: Author.

van Heugten, K. (2001). Social work: Its role and task. In M. Connolly (Ed.), New Zealand social work: Context and practice (pp. 3-17). Auckland, New Zealand: Oxford University Press.

Whiteford, G. (2010). Occupational deprivation: Understanding limited participation. In C. H. Christiansen \& E. A. Townsend (Eds.), Introduction to occupation: The art and science of living (2nd ed., pp. 303-328). Upper Saddle River, NJ: Pearson Education.

Wilcock, A. A. (2001). Occupational science: The key to broadening horizons. British Journal of Occupational Therapy, 64(8), 412-417.

Wilcock, A. A., \& Hocking, C. (2015). An occupational perspective of health ( $3^{\text {rd }}$ ed.). Thorofare, $\mathrm{NJ}$ : Slack.

World Health Organization. (1986). Ottawa Charter for health promotion. Geneva, Switzerland: Author.

World Health Organization. (2001). International classification of functioning, disability and health; ICF. Geneva, Switzerland: Author.

Yerxa, E. J., Clark, F., Jackson, J., Pierce, D., \& Zemke, R. (1990). An introduction to occupational science, a foundation for occupational therapy in the 21st century. Binghamton, NY: Haworth. 